\title{
Avaliação das propriedades físicas e mecânicas de concretos produzidos com vidro cominuído como agregado fino
}

\section{(Evaluation of physical and mechanical properties of concretes produced with ground waste glass as fine aggregate)}

\author{
D. A. R López ${ }^{1}$ C. A. P. de Azevedo' ${ }^{2}$ E. Barbosa Neto ${ }^{1}$ \\ ${ }^{1}$ UNISC, Av. Independência 2293, Santa Cruz do Sul, RS 96815-900 \\ ${ }^{2} U L B R A$, Av. Miguel Tostes 101, S. Luiz, Canoas, RS 92420-280 \\ dlopez@unisc.br
}

\begin{abstract}
Resumo
O presente trabalho insere-se na proposta da utilização racional dos recursos naturais não renováveis. Ele tem por objetivo, estudar a viabilidade técnica da utilização de vidro não reciclado como material agregado ao concreto, especificamente pela comparação das propriedades mecânicas de concretos fabricados com o novo componente, visando a sua utilização para fins estruturais. A comparação foi realizada por meio do estudo das propriedades mecânicas de concretos produzidos primeiramente com a substituição da areia por vidro moído e, numa segunda parte, pela adição do vidro moído sobre a massa de areia. Os resultados desta pesquisa mostraram que com a substituição de 5\% em peso do agregado fino (areia) por vidro numa granulometria variando entre $150-300 \mu \mathrm{m}$ houve um aumento de $\sim 60 \%$ na resistência à compressão do concreto fabricado, o que seria causado pela diminuição da porosidade do concreto por causa da penetração de vidro fino nos vazios. A utilização de outras faixas granulométricas acarretou aumentos menores, porém todos superiores aos valores apresentados pelo corpo de referência. Por outro lado, a adição de vidro moído na granulometria 150-300 $\mu \mathrm{m}$ em percentagens de até $20 \%$ sobre o peso do agregado fino (areia) teve um efeito bem diferente sobre o concreto produzido. A maior resistência à compressão, 56,6\% superior à do material de referência, foi obtida com a adição de 5\% em peso de vidro fino sobre o peso da areia. Acima desta percentagem, houve uma diminuição da resistência à compressão do concreto. Isto estaria influenciado pelo aumento da quantidade de material seco que deveria ser hidratado, uma vez que a relação água/cimento foi constante.

Palavras-chave: reciclagem de vidros, agregados para concretos, gerenciamento de lixo.
\end{abstract}

\begin{abstract}
This work consists on the proposal of rational utilization of non-renewable natural resources. It has the objective of studying the technical viability of utilization of ground waste glass as material aggregate to concrete specifically by the comparison of its effects on mechanical properties of concretes fabricated with the new component, aiming its utilization for structural purposes. The comparison was made on the basis of mechanical properties of produced concrete, both by replacing part of the sand by ground waste glass and by addition of ground waste glass over the mass of fine aggregate sand. The results of the research show that fine aggregate (sand) substitution for 5wt.\% of crushed glass with a particle size varying in the range150-300 $\mu \mathrm{m}$ produced an increase of $60 \%$ in the compressive strength of concrete. This would be explained by decrease of concrete porosity due to penetration of fine glass in the empty space gaps. The use of other particle sizes caused minor increases on strength, but the values were always superior to that of reference concrete. On the other hand, the addition of ground waste glass, with particle size varying between 150 and $300 \mu \mathrm{m}$ in percentages up to 20wt.\% over the mass of fine aggregate, had very different effects on mechanical properties of the produced concrete. The greater compression strength, 56\% superior to the reference concrete, was obtained by addition of 5 wt. of fine glass over the sand weight. The increase of the added glass mass produced a decrease of compressive strength of the produced concrete. This could be influenced by the increase of dry material that should have been hydrated, once the water/cement ratio was kept constant.
\end{abstract}

Keywords: reuse of ground waste glass, concrete, waste management.

\section{INTRODUÇÃO}

O Brasil produz em média 800 mil toneladas de vidro por ano, sendo que desse total 220.000 t/ano são recicladas, o que corresponde a $27,6 \%$ do total gerado. A quantidade de vidro descartado no lixo corresponde a $3 \%$ do total [1]. O principal mercado para a sucata de vidro é formado pelas vidrarias, que compram o material de sucateiros na forma de cacos ou recebem o material diretamente em suas campanhas de reciclagem. Porém, a reciclagem de vidro tem vários fatores limitantes como impurezas, custos de transporte proibitivos e mistura de sucatas de cores diferentes que são difíceis de serem separadas.

$\mathrm{O}$ uso de outros materiais no concreto, na forma de 
agregados fino ou grosseiro já foi estudado por vários pesquisadores. Alguns desses materiais são adicionados com o intuito de melhorar as características mecânicas dos concretos como a sílica, misturas de materiais pozolânicos, cinzas, pó de basalto, escórias, etc. [2]. Outros simplesmente são adicionados para utilizar a capacidade de encapsulamento do concreto, que por sua vez pode estar destinada à diminuição da periculosidade do material agregado (adição de resíduos classe I) ou diminuição da quantidade de material destinado ao aterro (adição de diferentes tipos de produtos poliméricos).

O uso de vidro já foi estudado e atualmente existem países utilizando este material como agregado fino no concreto. A Austrália, por exemplo, já utiliza o vidro moído proveniente do lixo em concretos para construção [3]. Foram apresentadas recomendações para o uso deste material em concretos no estado de Nova York [4]. No Brasil, esta forma de valorização desse recurso é pouco utilizada, uma vez que o aterro é uma opção muito barata e a disponibilidade de matéria-prima para materiais de construção é abundante.

Segundo Dyer e Dhir [5], sendo o vidro um material amorfo e contendo uma grande quantidade de silício e cálcio, torna o material, em teoria, pozolânico. Polley et al. [6], por exemplo, pesquisaram o uso de vidro reciclado como substituto do agregado fino (areia) no concreto. Os resultados dessa pesquisa indicaram que o vidro é um substituto satisfatório para agregados naturais finos em níveis de até $20 \%$ do agregado total em granulometrias variando entre 0,075 e $1,5 \mathrm{~mm}$, com resistências à compressão compatíveis com concretos do mesmo traço sem adição de vidro. Shao et al. [7] pesquisaram o uso de sílica, vidro finamente moído e cinzas volantes, mas em substituição ao cimento adicionados em proporções de até $30 \%$ em peso com tamanho de partícula abaixo de $0,15 \mathrm{~mm}$. Esses autores verificaram que o concreto produzido com a adição de vidro finamente moído $(<75 \mu \mathrm{m})$ tinha suas propriedades mecânicas melhoradas em função de reações pozolânicas. Para faixas mais grosseiras, o concreto produzido apresentava problemas de aumento de volume gerados pela reação álcali/sílica. Dyer e Dhir [5] também verificaram a influência destes 2 parâmetros. Eles afirmam que o elevado conteúdo de sódio e silício do vidro implica na possibilidade de que o concreto sofra uma reação álcali/sílica, o que faz com que o concreto se expanda durante a mesma. Babu e Prakash [2] constataram que o vidro pode influenciar a qualidade do concreto por outros efeitos que não o pozolânico e o da reação álcali/sílica. Eles constataram que os efeitos benéficos da adição do vidro estavam relacionados ao preenchimento de vazios entre os grãos do agregado fino (melhora do empacotamento das partículas). Já o efeito pozolânico aconteceria com vidros de granulometria fina $(<75 \mu \mathrm{m})$, uma vez que as partículas finas favorecem uma rápida e benéfica reação pozolânica. Para vidros com granulometria grosseira $(>0,75 \mathrm{~mm})$, a reação álcali/sílica aconteceria preferencialmente $[2,4,5]$.

O presente trabalho apresenta os resultados do uso de vidro moído, em determinadas faixas granulométricas, na fabricação de concreto e da influência desta utilização sobre as propriedades mecânicas do concreto produzido. Numa primeira fase, o vidro moído foi utilizado em substituição de parte do peso do agregado fino, sendo que na segunda fase, o vidro moído foi adicionado sobre o peso da areia. $\mathrm{O}$ concreto sem adição de vidro é tomado como referência para efeitos de comparação.

\section{MATERIAIS E MÉTODOS}

O vidro utilizado nos ensaios era proveniente do lixo da cidade de Canoas - RS e constituía-se de $100 \%$ do tipo soda - cal, com uma massa específica de $2,50 \mathrm{~g} / \mathrm{cm}^{3}$. Esse vidro foi obtido na forma de pedaços irregulares na Vidraria Santa Marina (SUBRASA-Canoas-RS). O material foi passado em um britador de mandíbula adquirindo uma granulometria com tamanho de partícula menor do que $10 \mathrm{~mm}$. Após essa etapa, o material foi moído num pulverizador até uma granulometria $100 \%$ abaixo de $2,5 \mathrm{~mm}$. A partir deste material, diferentes granulometrias foram separadas por peneiramento.

$\mathrm{O}$ agregado fino (areia) tinha um módulo de finura igual a 2,3 o que caracteriza uma areia de granulometria fina. $\mathrm{Na}$ Tabela I está apresentada a distribuição granulométrica da areia utilizada neste trabalho. A massa específica da areia era de $2,78 \mathrm{~g} / \mathrm{cm}^{3}$.

Como agregado graúdo foi usada brita basáltica, a qual revelou uma dupla numeração, indicando que se tratava de pedra britada números 1 e 2 .

Na primeira etapa foi pesquisado se haveria um tamanho de partícula para o vidro que acarretasse uma melhora da resistência à compressão do concreto produzido. Uma vez determinada esta granulometria, ela seria utilizada tanto

Tabela I - Distribuição granulométrica da areia utilizada. [Table I - Particle size distribution of used sand.]

\begin{tabular}{cccc}
\hline Peneiras & Massa & \multicolumn{2}{c}{$\%$ Retida } \\
\cline { 3 - 4 } (abertura em mm) & Retida (g) & Individual & Acumulada \\
\hline 25 & 0 & 0 & 0 \\
19 & 0 & 0 & 0 \\
12,5 & 0 & 0 & 0 \\
9,5 & 0 & 0 & 0 \\
6,3 & 0 & 0 & 0 \\
4,8 & 1 & 0 & 0 \\
2,4 & 15 & 2 & 2 \\
1,2 & 40 & 4 & 6 \\
0,6 & 95 & 10 & 16 \\
0,3 & 630 & 63 & 79 \\
0,15 & 210 & 21 & 100 \\
Fundo & 1 & 0 & 100 \\
\hline Total & 992 & Módulo & 2,03 \\
& \multicolumn{3}{c}{ de Finura } \\
\hline
\end{tabular}


nos ensaios de substituição da areia pelo vidro quanto nos de adição de vidro sobre o peso da areia. Dessa forma pesquisou-se nesta etapa a substituição de $5 \%$ do agregado fino (a areia) por vidro moído nas seguintes faixas granulométricas: $0-0,15 \mathrm{~mm} ; 0,15-0,30 \mathrm{~mm}$ e 0,30 $0,60 \mathrm{~mm}$. O cimento utilizado foi o CP IV-32 da marca VOTORAN. A dosagem foi realizada pela metodologia descrita por Silva [8] buscando obter um concreto com uma resistência à compressão de $8,23 \mathrm{MPa}$ aos 28 dias de cura. A relação água/cimento utilizada foi de 0,83 . Os corpos de prova foram confeccionados em moldes metálicos com formato cilíndrico com $10 \mathrm{~cm}$ de diâmetro e $20 \mathrm{~cm}$ de altura. Estas relações foram mantidas para todos os ensaios realizados neste trabalho.

$\mathrm{Na}$ segunda série de ensaios, foi determinada a percentagem adequada de substituição. Para isso foram realizadas substituições de $5,10,15$ e $20 \%$ do peso do agregado fino natural (areia) por vidro moído. A substituição foi realizada com vidro moído na faixa granulométrica com a qual se obteve maior resistência à compressão no $1^{\circ}$ parâmetro pesquisado.

$\mathrm{Na}$ terceira serie de ensaios foi realizada para determinar a influência da adição de vidro moído sobre o peso do agregado miúdo (areia) sobre as propriedades mecânicas do concreto. Para isto foram adicionadas respectivamente 5,10 , 15 e $20 \%$ em peso de vidro fino sobre o peso do agregado miúdo natural (areia). A adição foi realizada com vidro moído na faixa granulométrica que obteve maior resistência mecânica no $1^{\circ}$ parâmetro pesquisado.

Durante a moldagem dos corpos de prova, realizada segundo a norma NBR 5738/1994, foi determinada a consistência do concreto pelo abatimento do tronco de cone (Slump test) de acordo com a norma técnica NBR NM 67/1996.

Os ensaios de resistência à compressão foram realizados de acordo com a norma NBR 5739/1994 numa máquina universal de ensaios mecânicos com capacidade para 12 toneladas. Para todos os ensaios foram moldados quatro corpos de prova com cada granulometria utilizada, sendo que 3 deles eram submetidos aos ensaios de compressão e o quarto corpo destinado à determinação da absorção de água, porosidade e massas específicas seca segundo a norma NBR 9778/1987.

Para fins de comparação, foram confeccionados corpos de prova de referência sem a adição de vidro.

\section{RESULTADOS E DISCUSSÃO}

A apresentação dos resultados desta pesquisa é realizada em três módulos diferentes. Numa primeira etapa são apresentados os resultados da determinação de uma faixa granulométrica para o vidro com a qual se obteve maior resistência à compressão. Na segunda etapa, os resultados da substituição de areia por vidro são mostrados, e por último, os da adição de vidro sobre o peso da areia utilizada na confecção dos concretos.
Resultados da determinação da faixa granulométrica mais adequada

Na Fig. 1 estão apresentados os valores, da resistência média à compressão, obtidos dos corpos de prova com a substituição da areia por vidro moído, na proporção de $5 \%$ em peso. As granulometrias de vidro utilizadas foram: 0-150 $\mu \mathrm{m} ; 150-300 \mu \mathrm{m}$ e $300-600 \mu \mathrm{m}$. Os ensaios de compressão foram realizados após 7 dias de cura, uma vez que, segundo Giammusso [9], o concreto atinge $70 \%$ da sua resistência à compressão neste tempo de cura. Os resultados obtidos com os corpos de prova de referência satisfazem perfeitamente a resistência requerida para este tipo de material nos ensaios de compressão após sete dias de cura, conforme valores apresentados $[10,11]$. Os valores de resistência à compressão representam a média de 3 testes.

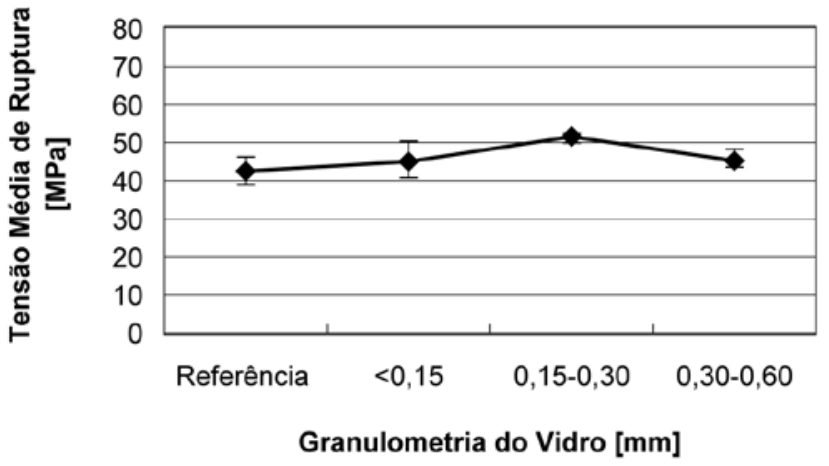

Figura 1: Resultados da substituição de 5 peso $\%$ da areia por vidro moído com diferentes faixas granulométricas sobre a resistência à compressão do concreto.

[Figure 1: Results of substitution 5 wt.\% sand by fine glass with different particle size on compressive strength of concrete.]

Os resultados obtidos com os corpos de prova contendo vidro moído mostram um aumento da tensão média de ruptura com o aumento da granulometria até atingir a faixa de $0,15-0,30 \mathrm{~mm}$, após a qual a tensão de ruptura diminui novamente se mantendo, porém, superior ao do corpo de prova de referência.

O aumento da tensão de ruptura, verificado com o uso de vidro com granulometria de $0,15-0,30 \mathrm{~mm}$, poderia ser causado pelo preenchimento de vazios pelo vidro fino (melhora no empacotamento das partículas). O espaço entre os agregados utilizados, principalmente entre a areia, estaria sendo ocupado pelo vidro, fazendo com que o material fique mais resistente à compressão. A diminuição da tensão de ruptura na granulometria $0,30-0,60 \mathrm{~mm}$ se explicaria pelo fato de que nesta faixa granulométrica o vidro já apresenta as características granulométricas da areia. De acordo com Shao et al. [7] o uso de vidros finos resulta numa interação química muito maior entre vidro e o cimento, o que por sua vez resulta num aumento da resistência à compressão (ou tensão média de ruptura). 
Tabela II- Efeito da substituição de 5 peso \% da areia por vidro sobre a absorção de água, índice de vazios e massa específica seca do concreto.

[Table II- Effect of replacement 5 wt.\% sand by fine glass on water absorption, porosity and dried specific mass of concrete.]

\begin{tabular}{cccc}
\hline $\begin{array}{c}\text { Granulometria do } \\
\text { Vidro Adicionado }\end{array}$ & $\begin{array}{c}\text { Absorção de } \\
\text { Água (\%) }\end{array}$ & $\begin{array}{c}\text { Índice de Vazios } \\
(\%)\end{array}$ & $\begin{array}{c}\text { Massa Específica } \\
\text { Seca }\left(\mathrm{g} / \mathrm{cm}^{3}\right)\end{array}$ \\
\hline CP Referência & 11,35 & 23,10 & 2,03 \\
$<0,15 \mathrm{~mm}$ & 11,32 & 22,90 & 2,15 \\
$0,15-0,30 \mathrm{~mm}$ & 8,93 & 19,44 & 2,35 \\
$0,30-0,60 \mathrm{~mm}$ & 9,29 & 20,13 & 2,29 \\
\hline
\end{tabular}

Obs.: Para estes ensaios foi utilizado apenas um corpo de prova.

O aumento da tensão média de ruptura apresentada pelo concreto com vidro de granulometria abaixo de 0,15 $\mathrm{mm}$ também poderia estar influenciado, teoricamente, pelo efeito pozolânico, embora neste trabalho esse efeito não tenha sido pesquisado. Segundo Shao et al. [7], o vidro finamente moído $(<0,15 \mathrm{~mm})$ satisfaz as condições de um material pozolânico e acima desta granulometria o vidro já seria muito grosseiro para ser considerado como pozolana.

Segundo Meyer e Xi [4] e Polley et al. [6], o uso de vidros com granulometrias grosseiras produz concretos com baixa resistência à compressão, quando usados como agregados, devido às características do vidro como: forma de fratura, características superficiais pobres e alta fragilidade. Partículas mais finas de vidro exibem, porém, uma forma mais regular e uma fragilidade muito reduzida. Esta observação se apóia nos resultados mostrados na Tabela II.

A Tabela II mostra uma relação inversamente proporcional entre a absorção de água, porosidade das amostras e o aumento da granulometria do vidro até a faixa $0,15-0,30 \mathrm{~mm}$. A diminuição da absorção se deve à diminuição da porosidade, indicando que o vidro preencheria os interstícios formados pelos agregados mais grosseiros (principalmente a areia) e fecha os poros (diminuição de vazios). Com o uso da faixa mais grosseira 0,30-0,60 mm, o preenchimento dos poros diminui, o que se reflete num aumento da porosidade do concreto, e consequentemente, da absorção de água.

Uma vez que o concreto obtido com o uso de vidro apresenta um índice de vazios menor, sua massa específica aumenta.

A observação anterior condiz com os resultados obtidos nos ensaios de abatimento (Slump Test) apresentados na Tabela III. O uso de vidro com faixa granulométrica entre $0,15-0,30 \mathrm{~mm}$ produziu um concreto com menor abatimento e, por conseguinte, obteve maior ganho na resistência mecânica nos ensaios de compressão uniaxial.

A diminuição do abatimento do concreto, com o vidro de granulometria $0,15-0,30 \mathrm{~mm}$, indica, por sua vez, que houve um aumento da consistência do concreto o que
Tabela III - Resultados da substituição de 5 peso \% de areia por vidro fino sobre o abatimento do concreto.

[Table III - Results of replacement of $5 w t . \%$ sand by fine glass on concrete slump.]

\begin{tabular}{cc}
\hline Corpos de prova & $\begin{array}{c}\text { Abatimento } \\
\text { (Slump) }[\mathrm{cm}]\end{array}$ \\
\hline Sem adição de vidro & 4,0 \\
Com substituição $(5 \%)$ - [<0,15 mm $]$ & 3,0 \\
Com substituição $(5 \%)$ - $[0,15-0,30 \mathrm{~mm}]$ & 2,0 \\
Com substituição $(5 \%)-[0,30-0,60 \mathrm{~mm}]$ & 3,0 \\
\hline
\end{tabular}

diminui a sua trabalhabilidade. Segundo Babu e Prakash [2] a redução da porosidade e da absorção de água do concreto faz aumentar a durabilidade deste material por meio da diminuição da permeabilidade, da redução do transporte de íons prejudiciais e do conteúdo de hidróxido de cálcio, resultando numa resistência maior ao ataque de sulfatos. Ainda, a melhoria da durabilidade do concreto leva a um aumento da proteção contra a corrosão do aço utilizado no concreto.

\section{Resultados da substituição de areia por vidro}

Com a determinação da faixa granulométrica 0,15 $0,30 \mathrm{~mm}$ (com a qual foi obtida a tensão média de ruptura mais elevada) foram realizados ensaios aumentando-se a percentagem de vidro moído substituindo a areia. A Fig. 2 apresenta os resultados destes ensaios.

Os resultados mostram um aumento progressivo da resistência à compressão com o aumento do teor de vidro no concreto, sendo que o aumento da tensão média para o concreto, com $20 \%$ de substituição, foi de $57 \%$ sobre a resistência do material de referência.

Este aumento na tensão média de ruptura está relacionado a vários fatores. A granulometria final do agregado fino resultante (areia + vidro) estaria mais próxima da curva granulométrica ideal, levando a uma considerável diminuição dos vazios do concreto. Em 


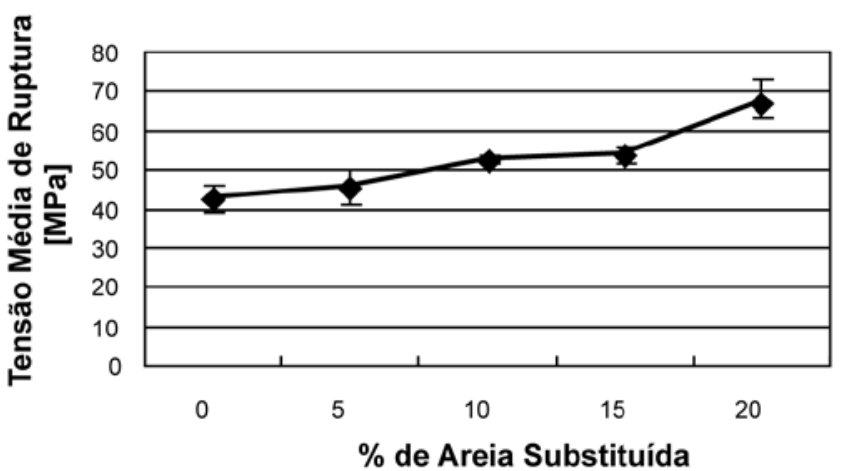

Figura 2: Efeitos da substituição de areia por vidro com granulometria $0,15-0,30 \mathrm{~mm}$, sobre a resistência de compressão do concreto.

[Figure 2: Substitution effects of sand by fine glass with particle size 0.15-0.30 $\mathrm{mm}$ on compressive strength of concrete.]

outras palavras, a substituição de areia por uma maior quantidade de vidro na granulometria $0,15-0,30 \mathrm{~mm}$ estaria fazendo com que a areia utilizada se aproximasse da sua curva granulométrica ideal, de modo que o agregado fino todo teria quantidades suficientes de partículas finas para preencher completamente os vazios entre as partículas mais grosseiras [2]. Também, uma maior quantidade de materiais finos (areia + vidro moído) leva ao aumento da superfície específica dos sólidos a serem hidratados, provocando uma redução do fator água/cimento, com o conseqüente aumento da tensão média de ruptura.

Estas observações estão sustentadas pelos dados apresentados na Tabela IV, onde se evidencia que o aumento da massa de vidro fino no concreto acarreta uma diminuição de $32 \%$ na absorção de água, de $26 \%$ no índice de vazios e um aumento de $26 \%$ na massa específica do concreto produzido. A diminuição do índice de vazios demonstra que o concreto está se tornando menos poroso em conseqüência da diminuição da relação água/cimento. Por sua vez, a diminuição desta última relação tem como efeito o aumento
Tabela V - Resultados da influência da substituição de areia por vidro na granulometria $0,15-0,30 \mathrm{~mm}$ sobre o abatimento do concreto.

[Table V-Results of replacement sand by glass with particle size 0.15-0.30 mm on concrete slump.]

\begin{tabular}{cc}
\hline$\%$ de areia substituída & $\begin{array}{c}\text { Abatimento (Slump Test) } \\
(\mathrm{cm})\end{array}$ \\
\hline 0 (Referência) & 4,0 \\
5 & 3,0 \\
10 & 2,0 \\
15 & 1,5 \\
20 & 1,0 \\
\hline
\end{tabular}

da resistência do concreto.

$\mathrm{Na}$ Tabela $\mathrm{V}$ se observa que o menor abatimento ocorreu no concreto contendo $20 \%$ de vidro com granulometria, o qual corrobora o maior ganho na resistência à compressão.

A diminuição dos valores de abatimento evidencia que uma maior proporção de vidro adicionado acarreta uma diminuição da relação água/cimento utilizada e, consequentemente, uma diminuição da trabalhabilidade do concreto produzido. A utilização de agregado fino de vidro reciclado demanda uma quantidade maior de água do que o uso de agregados finos naturais, já que há um aumento de área superficial a ser hidratada em função do aumento de partículas finas dentro do agregado fino.

\section{Resultados da adição de vidro sobre a massa de areia}

Os resultados da adição de vidro moído sobre a massa do agregado fino natural (areia) estão representados na Fig. 3, onde pode se observar a resistência à compressão em função da percentagem de vidro adicionado sobre o peso da areia.

Os resultados demonstram que a adição de $5 \%$ de vidro moído sobre o peso da areia aumentou a tensão média de ruptura em $56,6 \%$ sobre a resistência do material de

Tabela IV - Resultados da substituição de areia por vidro com granulometria 0,15-0,30 mm sobre a absorção de água, índice de vazios e massa específica seca do concreto. A densidade da areia é de 2,78 e a do vidro 2,50. [Table IV - Results of replacement $5 \mathrm{wt} . \%$ sand by fine glass particle 0.15-0.30 $\mathrm{mm}$ on absorption, porosity and dried specific mass of concrete. The sand density was 2.78 and that of glass 2.50.]

\begin{tabular}{cccc}
\hline \% de Areia Substituída & Absorção de Água (\%) & Índice de Vazios(\%) & $\begin{array}{c}\text { Massa Específica } \\
\text { Seca }\left(\mathrm{g} / \mathrm{cm}^{3}\right)\end{array}$ \\
\hline 0 (Referência) & 11,35 & 23,10 & 2,03 \\
5 & 11,32 & 22,90 & 2,15 \\
10 & 8,86 & 19,25 & 2,37 \\
15 & 8,80 & 18,04 & 2,47 \\
20 & 7,69 & 17,10 & 2,56 \\
\hline
\end{tabular}




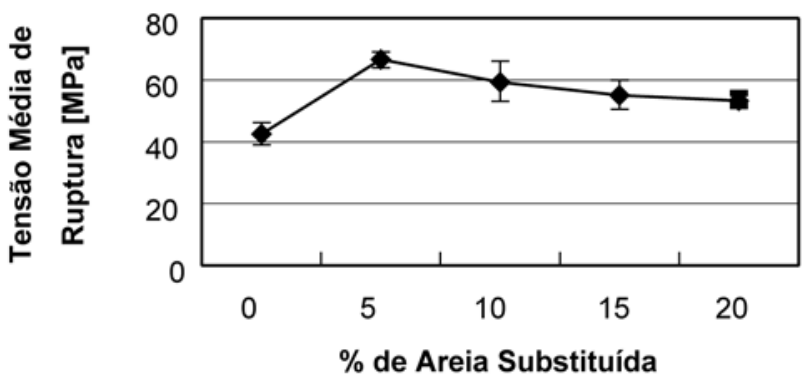

Figura 3: Resistência à compressão do concreto resultante da adição de vidro com granulometria $0,15-0,30 \mathrm{~mm}$ sobre o peso do agregado fino.

[Figure 3: Compressive strength of concrete with addition of glass with particle size of 0.15-0.30 mm over the sand mass.] redução da sua resistência à compressão.

Segundo Polley et al. [6] a diminuição da resistência à compressão do concreto, com o aumento da massa de vidro adicionada, pode ser associada à diferença na força de ligação entre a pasta e o agregado. As forças de ligação entre as partículas de vidro e a pasta são mais fracas se comparadas com a ligação da pasta com as partículas de agregados naturais. Logo, um aumento da massa de vidro no concreto aumenta a massa de agregado ligada mais fracamente à pasta.

$\mathrm{Na}$ Tabela VII, pode-se observar que o menor abatimento ocorreu no concreto com $5 \%$ de vidro adicionado sobre o peso do agregado fino, faixa esta que apresentou o maior ganho de resistência à compressão.

Tabela VI - Resultados dos ensaios de absorção de água, índice de vazios e massa específica seca e saturada em função da adição de vidro com granulometria de 0,15-0,30 mm sobre o teor de areia.

[Table VI - Results of replacement sand by fine glass with particle size 0.15-0.30 $\mathrm{mm}$ on absorption, porosity and dried specific mass of concrete.]

\begin{tabular}{cccc}
\hline$\%$ de areia substituída & $\begin{array}{c}\text { Absorção de Água } \\
(\%)\end{array}$ & $\begin{array}{c}\text { Índice de Vazios } \\
(\%)\end{array}$ & $\begin{array}{c}\text { Massa Específica Seca } \\
\left(\mathrm{g} / \mathrm{cm}^{3}\right)\end{array}$ \\
\hline 0 (Referência) & 11,35 & 23,10 & 2,03 \\
5 & 7,73 & 17,24 & 2,54 \\
10 & 7,80 & 17,38 & 2,53 \\
15 & 7,89 & 17,70 & 2,50 \\
20 & 8,15 & 17,92 & 2,49 \\
\hline
\end{tabular}

referência. A partir daí, o aumento da percentagem de vidro acarretou uma redução na tensão média de ruptura, porém, mantendo-se sempre acima da tensão média de ruptura do material de referência.

O aumento da tensão média de ruptura registrada com a adição de 5\% de vidro sobre a areia, pode ser relacionado diretamente com o efeito do preenchimento de vazios pelo aumento da quantidade de partículas no agregado já descrito anteriormente. Acima desta percentagem, o aumento progressivo da massa adicionada teria como efeito uma hidratação insuficiente dos sólidos acarretando o aumento dos vazios da massa, com a conseqüente redução da tensão média de ruptura dos corpos de prova, o que estaria corroborado pelos resultados mostrados na Tabela VI. Nesta Tabela, observa-se o aumento do índice de absorção de água, do índice de vazios e a redução da massa específica seca em função do aumento da percentagem de vidro moído adicionada ao concreto. Segundo Su e Chen [11], a adição de vidro moído sobre a massa de areia, em percentagens acima de 5\%, acarreta a presença de uma quantidade maior de material hidrofóbico (o vidro é um material naturalmente hidrofóbico). Isto faz com que a sua hidratação seja comprometida, o que por sua vez acarreta um aumento dos vazios da massa e a
Tabela VII: Efeitos sobre os ensaios de abatimento da adição de vidro moído com tamanho de partícula de $0,15-0,30 \mathrm{~mm}$ sobre a massa de areia.

[Table VII: Effects of addition of fine glass with particle size 0.15-0.30 mm over sand weight on concrete slump.]

\begin{tabular}{cc}
\hline \% de Vidro & $\begin{array}{c}\text { Abatimento (Slump) } \\
\text { Adicionado }\end{array}$ \\
\hline 0 (Referência) & 4,0 \\
5 & 1,0 \\
10 & 1,5 \\
15 & 1,5 \\
20 & 2,0 \\
\hline
\end{tabular}

\section{CONCLUSÕES}

Este trabalho apresenta os resultados do estudo da viabilidade técnica da utilização de vidro moído (em diferentes faixas granulométricas) retirado do lixo como agregado fino na fabricação de concretos, de modo a prover uma opção adicional para a revalorização do vidro. Os resultados são detalhados, primeiramente, em função da substituição da areia por vidro moído e, segundo, pela adição 
de vidro sobre a massa de areia. Os resultados obtidos nesta pesquisa permitem extrair as seguintes conclusões:

A substituição de $5 \%$ em massa do agregado fino do concreto (areia) por vidro moído (com diferentes faixas granulométricas) acarretou um aumento da resistência à compressão dos corpos de prova. Este aumento da tensão de ruptura mostrou-se dependente da granulometria do vidro, sendo que a faixa granulométrica de $0,15-0,30 \mathrm{~mm}$ apresentou os melhores valores. A utilização da faixa granulométrica 0,30-0,60 mm acarretou uma diminuição da tensão de ruptura dos corpos de prova. A tensão de ruptura atingida pelo corpo de prova confeccionado com vidro moído na granulometria $0,15-0,30 \mathrm{~mm}$ atingiu um valor $21 \%$ superior àquele do corpo de prova de referência (sem adição de vidro). $\mathrm{O}$ aumento do valor deste parâmetro poderia ser explicado pelo efeito do preenchimento dos vazios como conseqüência da acomodação das partículas de vidro fino. As observações aqui apresentadas estariam corroboradas pela diminuição da absorção de água, do índice de vazios, do abatimento e pelo aumento da massa específica do concreto produzido.

A adição de vidro moído com granulometria de $0,15-0,30 \mathrm{~mm}$, em substituição ao agregado fino (areia) em percentagens de 10,15 e $20 \%$ em peso, mostrou uma correlação diretamente proporcional entre aumento da percentagem de vidro e tensão de ruptura do corpo de prova. O valor máximo de tensão de ruptura foi atingido com a substituição em $20 \%$ em peso da areia, sendo este valor superior em $57 \%$ ao do corpo de prova de referência. $\mathrm{O}$ principal fator para o aumento da tensão de ruptura seria o preenchimento de vazios. A distribuição granulométrica final do agregado fino resultante (areia + vidro) seria tal que a mesma estaria próxima da granulometria ideal do material, o que levaria a uma diminuição considerável nos vazios do concreto, o que por sua vez se refletiria no aumento da tensão de ruptura dos corpos de prova. Os valores da absorção, índice de vazios, massa específica e do abatimento corroboram estas observações.

Com a adição de vidro moído sobre o peso da areia, na faixa granulométrica $0,15-0,30 \mathrm{~mm}$ em percentagens de 5 , 10,15 e $20 \%$ em peso, o máximo valor de tensão de ruptura (56,6\% superior ao valor obtido no ensaio do corpo de prova de referência) foi obtido com a adição de $5 \%$ de vidro. A partir daí, a tensão de ruptura diminuiu de forma constante com o aumento da adição de vidro. Todos os valores de tensão de ruptura medidos foram, porém, superiores ao valor obtido com o ensaio do corpo de referência. Este fenômeno estaria explicado pelo aumento da quantidade de material seco que devia ser hidratado. Também, a hidratação do concreto estaria sendo afetada pela adição de uma grande quantidade de material hidrofóbico (o vidro). Como nestes ensaios a quantidade de água adicionada na fabricação do concreto foi sempre constante, existiria uma deficiência de água para a hidratação e a relação água/cimento diminuiria. Com isto, haveria um aumento dos vazios nos corpos de prova, levando a uma diminuição da tensão de ruptura. Esta observação é corroborada pelo teste de slump destes corpos de prova, onde o aumento da adição de vidro acarretou um aumento do abatimento do concreto obtido.

Logo, esta pesquisa demonstra a viabilidade técnica da substituição do agregado fino por vidro moído. Entende-se aqui também, que serão necessárias novas pesquisas para a avaliação de todo o potencial da utilização do vidro moído como material agregado ao concreto. Por outro lado, o uso de vidro retirado do lixo como material agregado fino no concreto, estaria colaborando com a conservação de recursos naturais, com a diminuição da quantidade de lixo aterrada, assim como com o desenvolvimento de um material novo.

\section{REFERÊNCIAS}

[1] Cempre, Consórcio Empresarial para a Reciclagem, www.cempre.org.br, Internet em 15/04/2002.

[2] K. G. Babu, P.V. Prakash, Cem. Concr. Res. 25, 6 (1995) 1273.

[3] K. S. Crentsil, T. Brown, A. Taylor, Recycled glass as sand replacement in premix concrete, Ed. Eco-Recycled Australia and CSIRO (2001) 44.

[4] C. Meyer, Y. Xi, J. Mater. in Civil Eng. ASCE 11, 2 (1999) 89.

[5] T. D. Dyer, R. Dhir, J. Mater. in Civil Eng. ASCE 13, 6 (2001) 412.

[6] C. Polley, S. M. Cramer, R. V. De La Cruz, J. Mater. in Civil Eng. ASCE 10, 4 (1998) 587.

[7] Y. Shao, T. Lefort, S. Moras, D. Rodriguez, Cem. Concr. Res. 30, 1 (2000) 91.

[8] G. R. Silva, Manual de traços de concreto, Ed. Livraria Nobel S.A., S. Paulo, Brasil (1975) 396.

[9] S. E. Giamusso, Manual do concreto, Ed. PINI, S. Paulo, Brasil (1992) 161.

[10] P. K. Metha, P. J. Monteiro, Concreto: Estrutura, propriedades e materiais. Ed. PINI, S. Paulo, Brasil, (1994) 494.

[11] C. A. Azevedo, Avaliação da utilização de vidro cominuído como material agregado ao concreto, Dissertação de Mestrado, PPGEAM-ULBRA (2002) 120.

[12] N. Sun, J. S. Chen: Resources, Conservation and Recycling 35 (2002) 259.

(Rec. 06/05/2003, Rev. 16/08/2005, Ac. 10/09/2005) 